\title{
ASSÉDIO MORAL NAS RELAÇÕES DE TRABALHO NA ENFERMAGEM: OLHARES POSSÍVEIS A PARTIR DA COMPLEXIDADE
}

\author{
Silvana Sidney Costa $^{1}$, Karina Silveira de Almeida Hammerschimidt ${ }^{2}$, Alacoque Lorenzini Erdmann ${ }^{3}$
}

\begin{abstract}
RESUMO: Este artigo teve por objetivo refletir sobre o assédio moral nas relações de trabalho na Enfermagem, à luz da Complexidade de Edgar Morin. As considerações refletidas pelos referenciais complexos de Edgar Morin trazem à tona a importância da formação profissional do enfermeiro nos componentes curriculares da administração/gerenciamento. $\mathrm{Na}$ formação, há necessidade de construírem-se novos gerentes e líderes, solidários, tolerantes, serenos e que se tornem capazes de estabelecer o diálogo e a reflexão, considerando que todos os membros da equipe de enfermagem/saúde são importantes e indispensáveis ao sistema de cuidado complexo.
\end{abstract}

PALAVRAS-CHAVE: Enfermagem; Relações interpessoais; Recursos humanos de enfermagem.

\section{MORAL HARASSMENT IN LABOR RELATIONS IN NURSING: POSSIBLE LOOKS FROM THE COMPLEXITY}

\begin{abstract}
This paper aimed to reflect on the moral harassment in labor relations in Nursing, by the light of Edgar Morin's Complexity. The considerations reflected by Morin's complex references point out the importance of training in nursing curriculum components related to administration / management. In training it is necessary to build up new managers and leaders, supportive, tolerant, peaceful, and that become able to establish dialogue and reflection, considering that all members of the nursing/ health staff are important and indispensable to the system of complex care.
\end{abstract}

KEYWORDS: Nursing; Interpersonal relations; Nursing staff.

\section{ASEDIO MORAL EN LAS RELACIONES DE TRABAJO EN LA ENFERMERÍA: MIRADAS POSIBLES A PARTIR DE LA COMPLEJIDAD}

RESUMEN: Este artículo tuvo por objetivo reflexionar acerca del asedio moral en las relaciones de trabajo en la Enfermería, a la luz de la Complejidad de Edgar Morin. Las consideraciones reflexionadas por los referenciales complejos de Edgar Morin resaltan la importancia de la formación profesional del enfermero en los componentes curriculares de la administración. En la formación hay necesidad de construir nuevos gerentes y líderes, solidarios, tolerantes, serenos y que se vuelvan capaces de establecer el diálogo y la reflexión, considerando que todos los miembros del equipo de enfermería/salud son importantes e indispensables al sistema de cuidado complejo.

PALABRAS CLAVE: Enfermería; Relaciones interpersonales; Recursos hunanos de enfermería.

${ }^{1}$ Enfermeira. Doutor em Enfermagem. Professor da Escola de Enfermagem da Universidade Federal do Rio Grande-FURG. Líder do Grupo de Estudo e Pesquisa em Enfermagem Gerontogeriátrica-GEP-GERON/FURG. Pesquisadora do CNPq. ${ }^{2}$ Enfermeira. Doutoranda em Enfermagem pela FURG. Professor da Universidade Federal do Pampa-UNIPAMPA.

${ }^{3}$ Enfermeira. Doutor em Filosofia da Enfermagem. Livre Docente do Departamento de Enfermagem da Universidade Federal de Santa Catarina-UFSC. Pesquisadora do CNPq.

\author{
Autor correspondente: \\ Alacoque Lorenzini Erdmann \\ Universidade Federal de Santa Catarina \\ AC Cidade Universitária, s/n - 88040-970 - Florianópolis-SC-Brasil \\ E-mail: alacoque@newsite.com.br
}

Recebido: 13/02/10

Aprovado: 17/09/10 


\section{INTRODUÇÃO}

$\mathrm{O}$ assédio moral no trabalho tornou-se uma preocupação social. A discussão a respeito levou os trabalhadores assediados que, até então, sofriam em silêncio, a se sentir mais seguros, a expressar e a denunciar as práticas abusivas de que são vítimas ${ }^{(1)}$.

$\mathrm{Na}$ Enfermagem, tal situação pode apresentar-se do líder para com os outros trabalhadores: humilhando-os em público; humilhando-os, reservadamente, com ameaças; depreciando e denegrindo a sua imagem; distorcendo as informações, criando boatos e rumores maldosos e falsos; procedendo a diversas formas de insultos, como gritos, críticas, depreciação dos métodos de trabalho, banalização; criando ritos de disciplinamento e de poder; cerceando os direitos; restringindo, limitando, censurando e/ou retirando a autonomia; realizando cobranças absurdas; delegando-lhes tarefas inalcançáveis; desrespeitando; fiscalizando e controlando o seu trabalho abusivamente; com ausência de transparência para o outro; atribuir-lhes tarefas não condizentes com o cargo/função/área profissional ${ }^{(2)}$. Há necessidade de informar-se os trabalhadores da Enfermagem acerca do assédio moral e das sérias consequências que podem ter as vítimas deste sofrimento ${ }^{(3)}$.

A complexidade é uma maneira de entender o mundo, integrando as relações de coexistência entre os seres vivos e não vivos, integrando os conceitos de ordem e desordem, de uno e diverso, estabilidade e mudança, e a noção de incerteza. Ela pode ser entendida por meio de sete princípios fundamentais que se interligam, destacando-se o hologramático, o recursivo e o dialógico ${ }^{(4)}$.

Na prática da Enfermagem, seja de ensino, cuidativa, gerencial e/ou de pesquisa, as relações entre as partes e o todo se imbricam continuamente, lembrando a hologramacidade citada por Morin. Também a recursividade torna-se presente, quando produto e serviço se confundem e se complementam, nas dimensões de trabalho que os envolve. E, ainda, a dialógica faz-se necessária, quando se associam noções que parecem contraditórias, numa mesma realidade.

Entender o ser humano complexo exige aptidão para compreender os problemas, contextualizando-os, globalizando-os, interligando-os, entendendo a sua multidimensionalidade nas incertezas, reconhecendo a finitude de todos os seres humanos e da condição humana. Nesse sentido, questiona-se: que reflexões possibilitam maior compreensão sobre o assédio moral nas relações profissionais na Enfermagem? Para tal, inspirou-se nas noções de Complexidade de Edgar Morin, na busca por reflexão que possa contribuir nas discussões para um agir mais dinâmico, ético, solidário e complexo, principalmente nas ações gerenciais na Enfermagem. Então, o objetivo desta reflexão é refletir sobre o assédio moral nas relações de trabalho na enfermagem, à luz dos referenciais da Complexidade de Edgar Morin.

\section{Assédio Moral: vislumbrando possibilidades de compreendê-lo}

O que faz um ser humano trabalhador subjugar, maltratar, desprezar o outro ser humano trabalhador no ambiente de trabalho? Retorna-se aos escritos de Morin, quando ele chama a todos a refletir sobre esse ser humano, tão complexo.

O ser humano é um ser unidual que, ao mesmo tempo, é um ou mais de um; que é uma coisa e outra. É um duplo no qual, de cada um dos lados, concentra aspectos diferentes, complementares e contraditórios. É, ao mesmo tempo, sapiens e demens, afetivo, lúdico, imaginário, poético, histérico, sonhador e capaz de objetividades e de racionalidade, por ser um homo complexus. Seu surgimento se deu de forma complexa, resultante do processo de hominização, de "emergência da humanidade a partir da animalidade"(5:38).

Toda a complexidade histórica do ser humano lembra que cada indivíduo traz em si o mundo físico, o mundo químico, o mundo vivo, e, desses mundos, o ser humano encontra-se separado por seu pensamento, sua consciência e sua cultura. Por isso, não se pode conhecer o ser humano separando-o do universo ${ }^{(5)}$. Desta forma, um caminho que pode levar a condição humana a adquirir uma forma mais viva, ativa e integral do viver é ajudar cada ser humano a esclarecer sobre sua própria identidade, o que poderá ser mais clarificado por meio das formas de ser do sujeito, postas por Morin.

As formas de ser do sujeito são apresentadas por cinco princípios que caracterizam sua identidade. O primeiro permite a unidade subjetiva/objetiva do 'eu sou eu' e a distinção entre o exterior e o interior, além de permitir a autorreferência, ou seja, para referir-se a si, é preciso referir-se ao mundo externo. O segundo é o inseparável, que mantém a invariância do sujeito. Este princípio diz que, apesar das modificações que o corpo sofre ao longo do tempo, o sujeito continua o mesmo. E aqui, Morin fala da permanência da autor- 
referência, a despeito e através das transformações. $\mathrm{O}$ terceiro princípio é o da exclusão, onde o eu é único para cada um. O quarto é o de inclusão, fazendo com que se possa integrar na subjetividade do ser outros diferentes de si - outros sujeitos. Esse princípio possibilita que os seres humanos comuniquem-se e origina o quinto, que é o de comunicação, no qual existe uma dualidade implícita: em seu ego, o sujeito é potencialmente outro, sendo, ao mesmo tempo, ele mesmo. Essa compreensão permite considerar o outro não apenas como ego alter, ou seja, um outro sujeito, mas também como um alter ego - um outro eu mesmo ${ }^{(6)}$.

Essas reflexões morinianas sobre as formas de ser do sujeito talvez sirvam para compreendermos melhor as questões do assédio moral no trabalho, pois evidenciam a diversidade que envolve o ambiente de trabalho. As raízes do assédio moral, na cultura organizacional das empresas, estão centradas no contexto autoritário brasileiro.

As humilhações e maus-tratos remetem a uma afirmação da complexidade de que o sujeito é, por natureza, fechado e aberto. É fechado quando o egocentrismo torna o outro estranho para nós, e aberto, quando se vê o outro de forma altruísta e simpática. Dentro dessa possibilidade de abertura ou fechamento, pode ocorrer a sujeição, significando que "uma potência subjetiva (Estado, Pátria, Deus ou chefe) mais forte impõe-se no centro do programa egocêntrico e, literalmente subjuga o indivíduo, que acaba possuído dentro de si mesmo"(7:79). Essa também pode ser uma reflexão que leve a uma compreensão do assédio moral nas relações de trabalho da Enfermagem.

As relações entre as pessoas em um ambiente de trabalho apresentam-se de forma dinâmica, marcadas por tomadas de decisão abruptas, conflitos cotidianos, negociações inadequadas, sendo comuns discussões entre chefias e trabalhadores, e entre colegas de trabalho. Esses momentos mostram, no cotidiano da organização, a renovação do dinamismo organizacional. Nestes conflitos, busca-se o consenso das situações, porém, pode surgir o assédio moral, cultivado por intrigas, brigas, discussões, ou formação de grupos que fomentem a hostilidade.

Para compor uma organização, as relações interpessoais são vistas como "uma arborescência com ramificações complexas e efeitos aleatórios, incertos e indeterminados(...) $)^{\text {(8:496) }}$. Pode-se perceber os movimentos das relações interpessoais da Enfermagem como geradores de tensões. A equipe de Enfermagem possui bagagens culturais, sociais, técnicas, visões éticas e perspectivas diversificadas, inseridas numa rede de interconexões, interdependências, que direcionam a complexidade.

Precisa-se refletir sobre as formas do assédio moral na Enfermagem como ações complexas. Quando se reflete sobre a ação gerencial na Enfermagem, pode-se relacioná-la ao modo complexo de pensar, para apreciar os problemas sociais e políticos, além dos problemas organizacionais. O pensamento que afronta a incerteza pode esclarecer as estratégias do mundo incerto. O pensamento que une pode esclarecer uma ética da reunião e da solidariedade. O pensamento complexo tem, igualmente, os seus prolongamentos existenciais, que postulam a compreensão entre os seres humanos ${ }^{(6)}$.

As recentes ciências da complexidade, mais especificamente, o pensamento complexo, a partir de uma ruptura dos paradigmas simplificadores e acríticos da realidade, poderão auxiliar os trabalhadores da Enfermagem a construir uma nova coerência que incorpore tanto as teorias da administração quanto as práticas gerenciais inovadoras e integradoras ${ }^{(8)}$.

A lógica da complexidade de Edgar Morin tem direcionado muitas reflexões/discussões no campo da Saúde e na ciência da Enfermagem, uma vez que na Saúde/Enfermagem os fenômenos se apresentam em múltiplas dimensões ${ }^{(9)}$.

Dar a merecida importância ao assédio moral objetiva priorizar o ser humano no contexto organizacional, buscando compreender as contradições, incertezas e complementaridades inseridas nessa prática. Esta atitude deve colaborar para resgatar o valor do estar bem ou do estar melhor do trabalhador, como elemento essencial na relação do trabalho, e configurar um ambiente harmônico como imprescindível para o adequado desempenho no trabalho. A tolerância, a serenidade, o respeito e o amor ao outro propiciam relações solidárias e civilizadas, sendo estas importantes atitudes do ser gerente ${ }^{(9)}$.

Os gerentes se mostram pelo conhecimento e potencial de aprender e reaprender contínua e evolutivamente, pela autonomia no pensar, ser e fazer, por conhecer e dialogar com outros saberes, e por reconhecer suas limitações e possibilidades de avanços. Sendo assim, é oportuno refletir sobre a formação profissional, tendo como questionamentos: como esta pode auxiliar para compreensão do assédio moral? E para estimular a prevenção deste no ambiente do trabalho? Talvez o caminho necessite ser desenvolvido, 
principalmente, nas disciplinas de administração/ gerenciamento, por envolver o trabalho interdisciplinar, as relações interpessoais e a ética do trabalho em equipe.

\section{CONSIDERAÇÕES FINAIS}

Refletir sobre o assédio moral na Enfermagem direciona a aprofundar as questões relativas à condição humana, à noção de sujeito nos cenários das práticas em Saúde/Enfermagem e ao ambiente de trabalho mais saudável.

Como seres humanos formadores de outros seres humanos, como direcionadores de futuros enfermeiros, há necessidade de enxergarmos, com um novo olhar, principalmente o preparo dos futuros gerentes da Enfermagem. Assim, talvez as enfermeiras possam se tornar gerentes melhores e cuidar de forma mais digna e respeitosa dos trabalhadores que integram a equipe de Enfermagem. É importante promover relações mais solidárias com a equipe de trabalho, procurando legitimar as atitudes humanizantes, reconhecendo as fragilidades humanas e os limites de tolerância e convialidade na alteridade do ser. Os gerentes necessitam cultivar a serenidade, como sabedoria do viver com o outro, procurando promover um ambiente mais saudável.

\section{REFERÊNCIAS}

1. Aguiar ALS. Assédio moral: o direito à indenização pelos maus tratos e humilhações sofridos no ambiente de trabalho. São Paulo: LTr; 2005.

2. Dias HHZR. O "des"cuidado em saúde: a violência visível e invisível no trabalho da enfermagem [dissertação]. Florianópolis (SC): Universidade Federal de Santa Catarina; 2002.

3. Morin E. Introdução ao pensamento complexo. $2^{\mathrm{a}}$ ed. Lisboa: Instituto Piaget; 1995.

4. Morin E. Ciência com consciência. $8^{\mathrm{a}}$ ed. Rio de Janeiro: Bertrand Brasil; 2005.

5. Morin E. O método 5 - a humanidade da humanidade. Porto Alegre: Sulina; 2002.

6. Morin E. A cabeça bem-feita. Repensar a reforma. Reformar o pensamento. Rio de Janeiro: Bertrand Brasil; 1999.

7. Albuquerque MSV, Medeiros KR, Almeida SR, Fe- lisberto E. A expressão dos demônios de Morin. Rev. Bras. Saúde Matern. Infant. 2007;7(4):503-506.

8. Backes DS, Silva DM, Siqueira HH. O produto do serviço de enfermagem na perspectiva da gerência da qualidade. Rev Gaúcha Enferm. 2007;28(2):163-70.

9. Erdmann AL, Mello ALF, Meirelles BHS. As organizações de saúde na perspectiva da complexidade dos sistemas de saúde. Rev Bras Enferm. 2004;56(4):467-71. 